\title{
WHEN ARTISTS FAIL: A REPLY TO TRIVEDI
}

\author{
Sheila Lintott
}

In a recent article, 'An Epistemic Dilemma for Actual Intentionalism', Saam Trivedi argues that the way we ought to interpret artworks is best understood using the model proposed by hypothetical intentionalism. Trivedi alleges that actual intentionalism faces a serious dilemma, the upshot of which is that actual intentionalists must choose between redundancy and indeterminacy. Largely on the basis of this dilemma, he concludes that even if actual intentionalism is descriptively accurate, it is prescriptively untenable. In this essay, I focus on this alleged dilemma and argue that, contra Trivedi, it fails to undermine the prescriptive legitimacy of moderate actual intentionalism. That is, Trivedi's dilemma does not offer us a good reason to refrain from working to understand works of art under the methodological guidance of actual intentionalism.

IN A recent article, 'An Epistemic Dilemma for Actual Intentionalism', Saam Trivedi argues that the way we ought to interpret artworks is best understood on the model proposed by hypothetical intentionalism. ${ }^{\mathrm{I}}$ In support of this claim, Trivedi alleges that actual intentionalism faces a serious dilemma, the upshot of which is that actual intentionalists must choose between redundancy and indeterminacy. Largely on the basis of this dilemma, Trivedi concludes that even if actual intentionalism is descriptively accurate, it is prescriptively untenable. Therefore, he concludes that 'even if many interpreters currently follow [actual intentionalism's] recommendations, they should not do so' (p. 20I). I focus here on this alleged dilemma and argue that, contra Trivedi, it fails to undermine the prescriptive legitimacy of moderate actual intentionalism. That is, Trivedi's dilemma does not offer us a good reason to refrain from working to understand works of art under the methodological guidance of actual intentionalism.

Trivedi's opponents in this piece are Noël Carroll and proponents of his brand of moderate actual intentionalism. Carroll's moderate actual intentionalism relies in particular on a conception of art as a mode of communication, or, as Carroll puts it, conversation. ${ }^{2}$ Trivedi's precise disagreement with Carroll involves the relationship between actual intentionalism and an understanding of art as a mode

Saam Trivedi, 'An Epistemic Dilemma for Actual Intentionalism', British Journal of Aesthetics vol. 4I (200I), pp. I92-206.

2 Noël Carroll, 'Art, Intention, and Conversation', in Gary Iseminger (ed.), Intention and Interpretation (Philadelphia: Temple U.P., I992). 
of communication. Carroll thinks that the two are related, such that if it is true that our interest in artworks is often (usually) a conversational one, then we should agree that moderate actual intentionalism is the best theory of art interpretation. Trivedi agrees that our interest in artworks is adequately described as an interest in communication, but he disagrees that accepting such an interest as basic necessarily commits one to actual intentionalism. However, Trivedi presents the epistemic dilemma as a problem for all moderate actual intentionalists-philosophers who, according to Trivedi, restrict the scope of actual intentionalist interpretation to successful artworks. ${ }^{3}$ In Trivedi's sense, a successful artwork is one in which the artist's semantic intentions have been realized or embodied in the work.

The alleged dilemma relies on two claims. First, as I have said, on the claim that moderate actual intentionalists recommend their method of interpretation only for those artworks in which the artist has been successful. Secondly, Trivedi points out that artists sometimes fail to incorporate their semantic intentions in their work, so that the work ends up meaning something other than what its artist intended it to mean. To illustrate, Trivedi offers the 'simple example' of a sculptor who tries to make a curvaceous statue, but produces an angular-looking one instead (p. 196).

These claims, however, are questionable. In particular, it is reasonable to question the accuracy of Trivedi's representation of moderate actual intentionalism, his conception of artistic success, and also the theory of artistic intention to which he appeals. I consider these aspects of Trivedi's account and argue that they are inaccurate. Once these inaccuracies are cleared up, it will be plain to see that Trivedi's alleged epistemic dilemma for actual intentionalism is no dilemma at all. Before presenting my argument, I shall first state the dilemma as a whole. In my reconstruction of it, it runs as follows:

I. 'For any given artwork, either the artist's semantic intentions about work-meaning have been successfully embodied in it, or else they have not been successfully embodied in it' (pp. 197-198).

2. In order to figure out whether the artist's semantic intentions have been realized or not, we must check whether there is a fit between the workmeaning and the semantic intentions of the artist.

3. In order to figure out if there is a fit between work-meaning and the artist's

Trivedi refers to Robert Stecker, Artworks: Definition, Meaning, Value (University Park: The Pennsylvania State Press, 1997) and Richard Wollheim, Painting as an Art (Princeton: Princeton U.P., 1987), but a complete list would also include (at least) Noël Carroll, 'Intention and Interpretation: The Debate Between Actual and Hypothetical Intentionalists', Metaphilosophy vol. 3 I no. I/2 (2000), pp. 75-95 and Gary Iseminger, 'Actual vs. Hypothetical Intentionalism', Journal of Aesthetics and Art Criticism vol. 54, no. 4 (1996), pp. 319-326. 
semantic intentions, we must find the work-meaning independently of the artist's semantic intentions.

4. If there is no fit, then we can conclude that the artist's semantic intentions have not been realized.

5. If there is a fit, we can conclude that the artist's semantic intentions have been realized.

6. But, if we can figure out the work-meaning without referring to the artist's actual intentions, then we do not need the artist's semantic intentions to interpret the work.

7. And, if we cannot figure out work-meaning without referring to the artist's actual intentions, then we will not know whether the artist succeeded, nor will we know whether to approach the work as actual intentionalists or not.

Trivedi concludes that the actual intentionalist is compelled to choose between redundancy (6) as the one horn and indeterminacy (7) as the other horn of this epistemic dilemma. For if we can discern what the artwork means independently of an appeal to the semantic intentions of the artist, then such intentions are unnecessary to discern artwork meaning. On the other hand, if we cannot discern what the artwork means independently of knowing successfully realized semantic intentions, then it seems that we cannot tell if the artist has been successful. In cases where we cannot distinguish successful from unsuccessful artworks, since moderate actual intentionalists limit the scope of actual intentionalism to successful artworks, we do not know whether to resort to actual intentionalism or something else, perhaps hypothetical intentionalism. Thus, the issue at stake, according to Trivedi, concerns whether we, as audience members, can tell whether or not an artist has been successful and thus whether actual intentionalism is applicable.

However, Trivedi misconstrues moderate actual intentionalism. Moderate actual intentionalists do not hold that only successful works of art are proper subjects of actual intentionalist interpretation. The view is importantly different from this; it is rather that of the artist's intentions, only those that the work can have-express, embody, support-are truly relevant to a correct interpretation of the work. I take this to be is what Stecker means when he says that 'we can avoid attributing to works what an artist unsuccessfully intends to do in it by stipulating that only what an artist successfully intends (i.e. intentionally does) is part of what a work means', and what Iseminger means when he says that the 'meaning of a ... work is that meaning intended by the author which is compatible with the [work]'.5 So, contra Trivedi's suggestion, actual intentionalists are not required to discern ahead of time or even during early encounters with an artwork

Stecker, Artworks, p. I7I.

Iseminger, 'Actual vs. Hypothetical Intentionalism', p. 322. 
whether the artist has succeeded or not. Rather, the recommendation is, as far as I can tell, that we approach the artwork with the idea in mind that the artist has been at least partially successful in realizing her semantic intentions in the work and that we try to understand the work accordingly.

To explain further the point I am now trying to make, it is worthwhile to note that actual and hypothetical intentionalists agree on much regarding how we should interpret artworks. In fact, both admit that the intentions are relevant to a correct interpretation of the work, but they differ over the nature of those intentions (actual or hypothesized) and the degree to which intentions are relevant (authoritative or suggestive). Importantly, both focus primarily on the work itself. In addition to attending to the work itself, both consider (among other things) the context in which the work is presented, previous and perhaps subsequent works by the same artist, the climate of the times in which the artist worked, and the artist's public persona-including religious and political convictions. In practice, the major difference between actual and hypothetical intentionalists really amounts to this: if we were to learn with certainty that an artist intended a certain meaning and it is a meaning the work can have, then the actual intentionalist accepts it as the best meaning of the work. The hypothetical intentionalist, who views the artist simply as one critic among many, will only admit that the artist's intended meaning is one of a number of possible interpretations and will deny that it is necessarily the best one. In other words, the hypothetical intentionalist searches for the best hypothesis of artistically intended meaning where 'best' is understood as being the artistically superior interpretation of those the artist could have intended. ${ }^{6}$ So, an actual intentionalist will bypass an interpretation if it is one that the artist could have intended, but we know that she actually did not. But if the interpretation is artistically superior to other possibly or actually intended interpretations, then a hypothetical intentionalist may accept it.

Trivedi recommends that 'irrespective of whether the artist's intentions have succeeded or not, in experiencing and understanding artworks correctly, we should seek correct work-meaning primarily and not the artist's intentions' (p. 200). Moderate actual intentionalists agree, while maintaining that correct work-meaning is not independent of artistic intent. Noël Carroll points this out when he explains that 'for the modest actual intentionalist, close interpretive attention to the text is just the pursuit of the actual intentions of the artist; it is an error to think of close attention to the text and the search for actual intentions as opposed enterprises'. ${ }^{7}$ This explains how premise (2) - in order to figure out whether the artist's semantic intentions have been realized or not, we must check

\footnotetext{
6 For a thorough exposition of these conditions (epistemological and artistic) see Jerrold Levinson, 'Intention and Interpretation: A Last Look', in Intention and Interpretation, pp. 22 I-256.

Carroll, 'Intention and Interpretation', p. 77.
} 
whether there is a fit between the work-meaning and the semantic intentions of the artist-is misleading. It is misleading because it suggests that work-meaning and artistically intended meaning are necessarily two logically distinct entities, but the moderate actual intentionalist does not accept this: the moderate actual intentionalist holds that the meaning of an artwork is the meaning of the work that the artist intended it to have, provided that such meaning is compatible with or supported by the work itself. The main tenet of moderate actual intentionalism is that the work is what it is and means what it means largely, although not exclusively, due to what the artist intended it to be and to mean. From my discussion of this view, it should be clear that it is not as if the actual intentionalist needs some way to sort out the successful from the unsuccessful artworks prior to attempting to correctly experience and understand the work. Therefore, rather than:

I. 'For any given artwork, either the artist's semantic intentions about workmeaning have been successfully embodied in it, or else they have not been successfully embodied in it' (pp. 197-198)

the first premise of the alleged dilemma should read:

I'. For any given semantic intention, either it has been successfully embodied in the work or it has not been successfully embodied in the artwork.

From ( $\left.\mathrm{I}^{\prime}\right)$ we can see the focus of the next step should not concern determining whether the artwork as a whole embodies (all of) the artist's semantic intentions. Instead, the next concern should be over how to tell whether any given intention has been successfully realized in the work or not. But there is no epistemic dilemma involved in this determination. We can accomplish this by simply considering the various meanings the work could have and considering if one (or more) of them amounts to an embodiment, realization, or expression of the semantic intention in question. If so, then we have arrived at what the work-or at least part of it—does mean. If not, then either we have failed to notice a possible interpretation and should add it in order to accommodate the artist's intent, ${ }^{8}$ or else we could conclude that the artist has failed to realize that particular semantic intention.

Notice that this is a case where what the artist tells us about her intentions helps us to see something in the work. Admitting that this is possible, however, does not commit us to the extreme actual intentionalist view that artwork meaning is simply identical to the meaning its artist intended it to have. The meaning must be one that the work can have. In this case, calling our attention to some aspect(s) of the work allowed us to understand the work in a new way. This is not very mysterious, and critics often affect our experience of a work by pointing out or emphasizing certain aspects of it. 
Perhaps Trivedi would respond by saying that looking for the artist's intentions in an unsuccessful artwork is a waste of time, since they are not there. Therefore, the fact that artists can fail is clear evidence that we should avoid actual intentionalist interpretation, and opt instead to follow the hypothetical intentionalist method. Trivedi's straightforward claim that artists sometimes fail is uncontroversial. But the degree of failure necessary to make actual intentionalism a waste of time is so great that I am sceptical that it ever unintentionally occurs.

The claim that an artist either succeeds or fails to realize her semantic intentions in her work, upon which Trivedi's dilemma rests, presents us with a false dichotomy. Absolute success and absolute failure are not the only alternatives here. Moreover, it is rarely, if ever, the case that an artist in fact completely fails to express, realize, or embody her semantic intentions in her work.

I submit that successfully realized intentions are frequently, in art and elsewhere, a matter of degree. This is partly because intentions themselves are complicated and also because it is rarely, if ever, the case that an artist has one simple semantic intention. As Wollheim points out, artistic intentions are properly understood as follows.

'Intention' best picks out just those desires, thoughts, beliefs, experiences, emotions, commitments, which cause the artist to paint as he does. A further cause of error has been to think that these mental phenomena, in order to exercise causal power, have to be assembled into some inner picture which is a complete facsimile of the picture to be. No total preconception of the picture that is independent of all the engagement with the medium is a serious possibility. ${ }^{9}$

It seems to me that Trivedi has made just this mistake. In thinking that none of an artist's intentions are relevant to the interpretation of her work if she fails to achieve one desired aspect, he draws too narrow a field for artistic intention. While absolute success and absolute failure are at opposite poles on a spectrum of artistic achievement, they are not the only options. Rather than simply succeed or fail, an artist can succeed, fail, or hit a mark somewhere in between. Given the complex nature of artistic intentions (and any intention) and the variables involved in the execution of that intention, the possibility of partial success seems by far the most likely. For all but cases of total failure, it is reasonable to think that we can frequently find evidence in a work of partially to wholly realized artistic intent.

Therefore, what we find is not the meaning of the work independent of the meaning its artist intended. Rather, we focus our attention primarily on the work and in doing so find evidence of artistic success. It might be the case that an artist's work fails to capture every detail exactly as she wished, but how such

9 Richard Wollheim, Painting as An Art (Princeton: Princeton U.P., 1987). 
failure amounts to a complete failure I cannot see. As Carroll has pointed out, we can find evidence of failed intentions within a work, ${ }^{10}$ and so too can we see evidence of partially realized intentions. This is so because, as neoWittgensteinians such as Colin Lyas argue, intentions are not causes that lie completely outside of their effects. ${ }^{11}$ Moreover, it is highly unlikely for an artist to completely fail to realize her semantic intentions. Artists can fail, and can fail drastically. ${ }^{12}$ Nonetheless, my suspicion is that cases of drastic failure, say making an artwork pink instead of blue, ${ }^{13}$ are extremely rare. But even drastic failure is not the same thing as complete artistic failure, as drastic failure need not be a case in which none of the artist's semantic intentions have been realized. This is why comments such as, 'I see what the artist was trying to do here', are frequently uttered by critics and audience members alike; and even if such sentiments are followed by claims that the artist did not completely achieve the desired effect, the claim makes perfect sense.

Trivedi might refer in his defence to his own example and argue that we cannot tell, for example, whether the artist intended the sculpture to be curvaceous or angular simply by looking at the artwork in the gallery. We need two independent notions of meaning-artwork-meaning and artistically intended-and only then can we tell, via comparison, whether the artist has succeeded. But this response only serves to highlight the problem. Trivedi's statue is analogous to something like a completely failed conversation: a conversation, that is, in which there are no clues of what the interlocutors intended to say to be found in what they did say. But does this not sound like an extremely unlikely occurrence? What would have to be the state of mind of an individual whose words bear no relation to the meaning she intended to convey? Unless we are dealing with either a case of trickery or a case of someone who lacks (all of) the requisite language skills, then it seems we would call into question the sanity of the individual.

Trivedi's example of the curvaceously intended but angular-looking sculpture does not help his case, as the likes of it are rarely seen in practice. Moreover, although this may seem like a case of complete artistic failure, i.e. where the artist has failed to embody her semantic intentions in the work, it is not clear that it is such a failure. What are the properties of a sculpture? Size, shape, texture, colour, sheen. The sculptor in Trivedi's example has missed somehow in the execution of his intention to make the sculpture curvaceous, but perhaps the sculptor has got some or all of the rest of it right. If this is the case, then those intentions are

\footnotetext{
ro See Carroll's discussion of Thomas Kuhn's use of 'weaned' where 'nurtured' was the appropriate word choice in his 'Art, Intention, and Conversation', in Intention and Interpretation, p. Iоo.

${ }^{11}$ Colin Lyas, 'Wittgensteinian Intentions', in Intention and Interpretation, pp. I32-I 5 I.

${ }_{12}$ I am grateful to Susan Feagin for bringing this point to my attention.

${ }_{13}$ The reference, of course, is to Beardsley's example in Aesthetics: Problems in the Philosophy of Criticism (New York: Harcourt, Brace \& World, I958), p. 20.
} 
relevant to the interpretation of the sculpture. There is no reason to think that all of an artist's intentions need to be realized in order for some of her intentions to be relevant to the interpretation of her work. ${ }^{14}$

In sum, contra Trivedi, I have argued that actual intentionalists need not be able to tell whether an artist has successfully realized her semantic intentions before experiencing and interpreting the work. The pertinent issue is whether a given intention is relevant, not whether the artist has fully succeeded or not. Secondly, if need be, I have argued that we can tell if an artist has fulfilled some of her semantic intentions without appealing to the two separate notions of artwork-meaning and artistically intended meaning. And although we can find many good and convincing clues in the work itself of artistic intent, frequently information gleaned from artists can tell us even more about the work. Hence, the alleged dilemma has been dissolved. Now we see it should read as follows:

$\mathrm{I}^{\prime}$. For any given semantic intention, either it has been successfully embodied in the work or it has not been successfully embodied in the work.

$2^{\prime}$. In order to figure out whether one of the artist's semantic intentions has been realized or not, we must check whether there is a fit between what the work could mean and that semantic intention of the artist.

$3^{\prime}$. In order to figure out whether there is a fit between what the work could mean and that semantic intention of the artist, we must find out what the work could mean and then discern whether the artist's semantic intention is compatible with one (or more) of the things the work could mean.

$4^{\prime}$. If no possible meaning of the work is compatible with or supports the semantic intention in question, then we can conclude that the artist's semantic intention has not been realized.

$5^{\prime}$. If there is a possible meaning of the work that is compatible with or supports the semantic intention in question, then we can conclude that the artist's semantic intention has been realized.

However, the problems that Trivedi claims follow from his dilemma no longer follow. For, if $\left(4^{\prime}\right)$ the intention is incompatible with or unsupported by the work, then

$6^{\prime}$. We can conclude that this particular intention is not relevant to the interpretation of the artwork.

\footnotetext{
${ }_{4}$ And, as Carroll points out (speaking of Beardsley's example of a pink statue that was allegedly intended by the artist to be blue), we might legitimately question whether the sculptor in question is being honest when she reports that she intended the sculpture to be curvaceous. It seems doubtful that she is, and actual intentionalists are not interested in insincere or ignorant reports about artistic intentions; rather, they are interested in the artist's actual intentions, whether she admits them or not (Carroll 'Art, Intention, and Conversation', p. 99).
} 
And if $\left(s^{\prime}\right)$ the intention is compatible with or supported by the work, then

$7^{\prime}$. We can conclude that this particular intention is relevant to the interpretation of the artwork.

Therefore, contra Trivedi's allegations, there is no redundancy and no indeterminacy. There is no redundancy because looking for work-meaning and looking for the artist's actual intentions are not two distinct procedures. There is no indeterminacy because we know how to tell if a given intention is compatible with the work, which is all we need to do. In short, the question the actual intentionalist needs to answer is not which of all artworks are the successful ones, but rather which of the artist's intentions are successfully embodied in the work. The actual intentionalist stands to learn about the work by learning about its genesis and to enrich their understanding of the work by communing with the artist responsible for it being what and how it is. The artist's intentions are therefore not redundant, and looking for them does not confront us with any indeterminacy. ${ }^{15}$

Sheila Lintott, Department of Philosophy, sis4 Helen C. White Hall, 6oo North Park Street, University of Wisconsin—Madison, Madison, WI 53706, USA. Email: slintott@ facstaff.wisc.edu

Is My thanks to Noël Carroll and Jinhee Choi for helpful comments on an earlier version of this essay. 